\title{
An Isolate of Alternaria alternata That Is Pathogenic to Both Tangerines and Rough Lemon and Produces Two Host-Selective Toxins, ACT- and ACR-Toxins
}

\author{
A. Masunaka, K. Ohtani, T. L. Peever, L. W. Timmer, T. Tsuge, M. Yamamoto, H. Yamamoto, and K. Akimitsu
}

\begin{abstract}
First, second, seventh, and eighth authors: United Graduate School and Faculty of Agriculture, Kagawa University, Miki, Kagawa 761-0795, Japan; third author: Department of Plant Pathology, Washington State University, Pullman 99164; fourth author: University of Florida, Institute of Food and Agricultural Sciences, Citrus Research and Education Center, Lake Alfred 33850; fifth author: Graduate School of Bioagricultural Sciences, Nagoya University, Chikusa, Nagoya 464-8601, Japan; and sixth author: Faculty of Agriculture, Okayama University, Okayama 700-8530, Japan.
\end{abstract}

Accepted for publication 3 November 2004.

\begin{abstract}
Masunaka, A., Ohtani, K., Peever, T. L., Timmer, L. W., Tsuge, T., Yamamoto, M., Yamamoto, H., and Akimitsu, K. 2005. An isolate of Alternaria alternata that is pathogenic to both tangerines and rough lemon and produces two host-selective toxins, ACT- and ACR-toxins. Phytopathology 95:241-247.

Two different pathotypes of Alternaria alternata cause Alternaria brown spot of tangerines and Alternaria leaf spot of rough lemon. The former produces the host-selective ACT-toxin and the latter produces ACR-toxin. Both pathogens induce similar symptoms on leaves or young fruits of their respective hosts, but the host ranges of these pathogens are distinct and one pathogen can be easily distinguished from another by

ACR-toxin. Isolate BC3-5-1-OS2A carries both genomic regions, one of which was known only to be present in ACT-toxin producers and the other was known to exist only in ACR-toxin producers. Each of the genomic regions is present on distinct small chromosomes, one of $1.05 \mathrm{Mb}$ and the other of $2.0 \mathrm{Mb}$. Alternaria species have no known sexual or parasexual cycle in nature and populations of A. alternata on citrus are clonal. Therefore, the ability to produce both toxins was not likely acquired through meiotic or mitotic recombination. We hypothesize that a dispensable chromosome carrying the gene cluster controlling biosynthesis of one of the host-selective toxins was transferred horizontally and rearranged by duplication or translocation in another isolate of the fungus carrying genes for biosynthesis of the other host-selective toxin.
\end{abstract} comparing host ranges. We isolated strain BC3-5-1-OS2A from a leaf spot on rough lemon in Florida, and this isolate is pathogenic on both cv. Iyokan tangor and rough lemon and also produces both ACT-toxin and
Additional keyword: anastomosis.
Alternaria species cause four diseases of citrus including Alternaria brown spot of tangerines (Citrus reticulata Blanco), Alternaria leaf spot of rough lemon ( $C$. jambhiri Lush.) and rangpur lime (C. limonia Osbeck), Alternaria black rot of many citrus cultivars, and Mancha foliar of Mexican lime ( $C$. aurantifolia Swingle) $(3,23,26,33)$. Alternaria brown spot affects many tangerines, grapefruit ( $C$. paradisi Macf.), and their hybrids resulting in lesions on, and abscission of, immature fruit and leaves. Alternaria leaf spot of rough lemon produces similar symptoms to those described above on leaves and fruits. The fungi causing brown spot and leaf spot are morphologically similar, have small catenulate spores, and are considered to be distinct pathotypes of the same species, A. alternata (26). Both brown spot and leaf spot pathogens produce host-selective toxins (HSTs) and the host range of each is very narrow $(3,14-16)$.

Alternaria and Cochliobolus species are well-known producers of HSTs $(21,31,34,35,37)$. HSTs are low molecular weight, secondary metabolites that are produced during germination of spores on plant surfaces. These toxins have high specificity and toxicity and induce cell death at $10^{-9}$ to $10^{-8} \mathrm{M}$ when applied to susceptible plants. The selective toxicity of HSTs is correlated with the pathogenicity reactions of the fungi that produce them (14-16), and HSTs are demonstrated pathogenicity factors $(13,17,21$,

Corresponding author: K. Akimitsu; E-mail address: kazuya@ag.kagawa-u.ac.jp

DOI: 10.1094/PHYTO-95-0241

(C) 2005 The American Phytopathological Society
$32,34,35,37)$. Nishimura and Kohmoto (21) proposed that these Alternaria strains should be designated as pathotypes of A. alternata. Despite the evolutionary relatedness of these host-specific Alternaria strains, each produces a chemically distinct HST and they can be easily distinguished by comparing host range. The chemical structures of HSTs from six pathotypes of A. alternata including ACT- and ACR-toxins (Fig. 1) have been elucidated $(4,15,19)$, and we have identified $A C T T$ genes that are thought to be involved in the biosynthesis of ACT-toxin (18).

Three major evolutionary lineages of A. alternata cause brown spot and leaf spot of tangerines and rough lemon in Florida $(24,26)$. Two of these lineages are associated with brown spot of tangerines (the SH1 and SH4 lineages) and the other with leaf spot of rough lemon ( $\mathrm{HC} 1$ lineage). All three can be recovered from healthy rough lemon tissue in Florida, but most isolates are nonpathogenic on either tangerine or rough lemon (24; T. L. Peever, unpublished data). Abandoned citrus groves on rough lemon rootstocks in Florida may be located adjacent to tangerine groves. This proximity of both hosts provides an opportunity for each pathotype to interact in a common host (rough lemon). Since all lineages can occur in a common host, we predict that an isolate of A. alternata may evolve that would possess genomic regions carrying genes responsible for the biosynthesis of both ACT- and ACR-toxins. One genomic region carrying either ACTT or ACR biosynthetic genes could have been transferred to a cell carrying the other genomic region during cell fusion through hyphal anastomosis. To test this hypothesis, we screened isolates of A. alternata from citrus groves in Florida to identify strains pro- 
ducing both ACT- and ACR-toxins and examined the pathogenicity and presence of predicted genes responsible for the biosynthesis of each HST.

\section{MATERIALS AND METHODS}

Fungal isolates and host materials. Thirteen isolates of the tangerine pathotype (isolate numbers SH11, 12, 13, 14, 15, 18, 19, 20, 21, EV10, 13, 14, and 24) were isolated from brown spot lesions on Minneola tangelo $(C$. paradisi $\times C$. reticulata $)$, and six isolates of the rough lemon pathotype $(\mathrm{HC} 1,7,8, \mathrm{BC} 19,27$, and 35) were isolated from leaf lesions on rough lemon in central Florida (Table 1). Three isolates of nonpathogenic A. alternata (HC14, BC17, and 36) were isolated from leaf lesions on rough lemon from the same locations (Table 1). Isolate BC3-5-1-OS2A was isolated from a leaf lesion on rough lemon at the Baseball City location (Table 1). Tangerine pathotype isolate SH20 and rough lemon pathotype isolate $\mathrm{HCl}$ were selected as reference strains for each pathotype (18). In addition, laboratory stocks (12) of nonpathogenic A. alternata isolate O-94, Japanese pear pathotype isolates $15 \mathrm{~A}$ and $\mathrm{Nu} 88-22$, strawberry pathotype isolates NAF-3 and NAF-8, tomato pathotype isolates 91080804 and AL4, apple pathotype isolates $\mathrm{O}-159$ and AM-1, tobacco pathotype isolates 122-2 and AT-204, rough lemon pathotype isolate AC325 (2), and ATCC58171 for A. citri (11) were used in this study (Table 1). All isolates were stored in $25 \%$ glycerol at $-85^{\circ} \mathrm{C}$ and cultures were initiated from the stocks for each experiment. Leaves for inoculation studies were obtained from cv. Iyokan tangor (C. iyo hort. Ex Tanaka) and rough lemon grown in the greenhouse as described previously $(18,22)$. Iyokan tangor is sensitive to ACT-toxin and susceptible to the tangerine pathotype of A. alternata $(14,18)$. Rough lemon is sensitive to ACR-toxin and susceptible to the rough lemon pathotype of A. alternata $(2,14,18,22)$. The two hosts were insensitive to the toxin produced by the other pathotype.

Toxin production and pathogenicity. The pathogenicity of each isolate was tested using the spray inoculation assay of Kohmoto et al. (15). Isolates were grown in potato dextrose broth (PDB), and mycelial mats were washed three times with sterile water to prepare conidia as described previously $(15,18)$. The pathogenicity of each isolate was determined by spray inoculation of a conidial suspension $\left(1 \times 10^{5}\right.$ conidia/ml $)$ on detached leaves of citrus cv. Iyokan tangor and rough lemon $(15,18)$. Inoculated leaves were incubated in a moist chamber for $48 \mathrm{~h}$ at $24^{\circ} \mathrm{C}$ in the

\section{ACT-toxin}

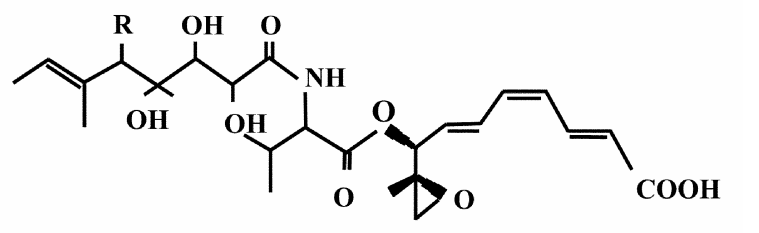

ACR-toxin I

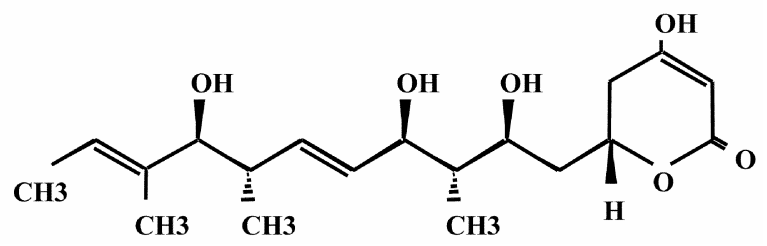

Fig. 1. Chemical structures of ACT-toxin and ACR-toxin-I produced by the tangerine pathotype and rough lemon pathotypes of Alternaria alternata $(4,15,19)$. dark, and the development of necrotic spots on the leaves was monitored.

Toxin production by each isolate was analyzed by highperformance liquid chromatography (HPLC) and thin-layer chromatography (TLC) as previously described $(2,4,15,18,19)$ with some modifications. Stationary cultures of each isolate were initiated in $50 \mathrm{ml}$ of modified Richards' medium $(15,16,18)$ at $24^{\circ} \mathrm{C}$ for 25 days, and each culture filtrate was collected through four layers of gauze. ACT-toxin and ACR-toxin were extracted from the culture filtrates using ethyl acetate as described by Kohmoto et al. (15). Ethyl acetate extracts of culture filtrates were analyzed using HPLC (Model 880 PU, Japan Spectroscopic, Tokyo) to detect ACT-toxin. After passing through Sep-Pak Plus C18 Cartridge (Waters, Milford, MA), the extracts were analyzed by HPLC on a Develosil ODS-5 column (4.6 by $250 \mathrm{~mm}$, Nomura Chemical, Nagoya, Japan) using a gradient solvent system composed of acetonitrile/deionized water/acetic acid (from $30: 70: 1$ to $60: 40: 1, \mathrm{vol} / \mathrm{vol}$ ) for $30 \mathrm{~min}$ at a flow rate of $1 \mathrm{ml} / \mathrm{min}$ (15). Peaks were detected by monitoring absorbance at $290 \mathrm{~nm}$. An authentic standard of ACT-toxin (Fig. 1) was prepared from culture filtrates of isolate $\mathrm{SH} 20$ as described previously (15).

The presence of ACR-toxin in the extracts was determined by the TLC system using silica gel 60 F254 TLC plates (Merck, Darmstadt, Germany). Ethyl acetate extracts were developed using a solvent system of benzene/acetone/acetic acid (60:40:1, $\mathrm{vol} / \mathrm{vol}$ ), and ACR-toxin was detected as a purple spot under $254 \mathrm{~nm}$ UV. An authentic preparation of ACR-toxin (Fig. 1) was prepared from culture filtrates of isolate $\mathrm{HC} 1$ as described previously $(2,4,19)$.

Elution of the corresponding peak for ACT-toxin and the TLC spot for ACR-toxin were tested for their selective toxicities on different hosts by the leaf necrosis assay described previously

TABLE 1. Isolates of Alternaria spp. used in this study

\begin{tabular}{|c|c|c|}
\hline Isolate & Pathotype & References \\
\hline BC3-5-1-OS2A & Dual pathotypes & This study \\
\hline SH11 & Tangerine & $(18)$ \\
\hline SH12 & Tangerine & $(18)$ \\
\hline SH13 & Tangerine & (18) \\
\hline SH14 & Tangerine & (18) \\
\hline SH15 & Tangerine & (18) \\
\hline SH18 & Tangerine & $(18)$ \\
\hline SH19 & Tangerine & $(18)$ \\
\hline $\mathrm{SH} 20$ & Tangerine & (18) \\
\hline $\mathrm{SH} 21$ & Tangerine & (18) \\
\hline EV10 & Tangerine & (18) \\
\hline EV13 & Tangerine & (18) \\
\hline EV14 & Tangerine & (18) \\
\hline EV24 & Tangerine & (18) \\
\hline $\mathrm{HC} 1$ & Rough lemon & (18) \\
\hline $\mathrm{HC} 7$ & Rough lemon & (18) \\
\hline $\mathrm{HC} 8$ & Rough lemon & (18) \\
\hline BC19 & Rough lemon & (18) \\
\hline $\mathrm{BC} 27$ & Rough lemon & (18) \\
\hline BC35 & Rough lemon & (18) \\
\hline AC 325 & Rough lemon & (2) \\
\hline $\mathrm{HC} 14$ & Nonpathogen & (18) \\
\hline BC17 & Nonpathogen & (18) \\
\hline BC36 & Nonpathogen & (18) \\
\hline O-94 & Nonpathogen & (2) \\
\hline ATCC58171 & Black rot pathogen & (11) \\
\hline $15 \mathrm{~A}$ & Japanese pear & (12) \\
\hline Nu88-22 & Japanese pear & (12) \\
\hline NAF-3 & Strawberry & (12) \\
\hline NAF-8 & Strawberry & (12) \\
\hline 91080804 & Tomato & (12) \\
\hline AL-4 & Tomato & (12) \\
\hline O-159 & Apple & (12) \\
\hline AM-1 & Apple & (12) \\
\hline $122-2$ & Tobacco & (12) \\
\hline AT-204 & Tobacco & (12) \\
\hline
\end{tabular}


$(15,18)$. Toxicity of culture filtrates was also determined by the leaf necrosis assay $(15,18)$. The supernatant of culture filtrates harvested by centrifugation at $1,500 \times g$ for $5 \mathrm{~min}$, or purified toxin samples, was diluted in distilled water $(1: 100, \mathrm{vol} / \mathrm{vol})$ and $30 \mu \mathrm{l}$ was placed on a puncture-wounded site with a needle on the lower surface of leaves of Iyokan tangor and rough lemon. Leaves were incubated in a moist chamber at $24^{\circ} \mathrm{C}$ in the dark, and necrosis development on leaves was observed after $48 \mathrm{~h}$.

DNA manipulations. Isolation of total genomic DNA of $A$. alternata for genomic polymerase chain reaction (PCR) and genomic Southern blot hybridization was carried out as described previously $(11,18)$, and nucleic acid manipulations followed standard procedures (30). Genomic DNA $(5 \mu \mathrm{g})$ was digested with 10 units of restriction enzyme EcoRV (Takara, Shiga, Japan) and fractionated in $0.8 \%$ agarose gels. Fractionated DNA was transferred to Hybond $\mathrm{N}^{+}$membrane (Amersham Biosciences, Piscataway, $\mathrm{NJ}$ ) by capillary transfer (30).

The ACTT-specific genes ACTT1 and ACTT2, present only in ACT-toxin-producing isolates, were prepared as described previously (18) using ACTT1F2 (5'-CACAGGCTATCTTCACATGC$\left.3^{\prime}\right)$ and ACTT1R2 (5'-CGTAGCTCCATAGCATTGCT-3') for amplification of ACTT1 and ACTT2F1 (5'-AGATGCAGCAGCCCATCATT-3') and ACTT2R1 (5'-CGACTGCAGATATTTCATCC$3^{\prime}$ ) for amplification of ACTT2. The specific DNA fragment, present only in ACR-toxin-producing isolates, was designated RP10-2. This fragment was amplified from isolated 1.5 Mb dispensable chromosome from the isolate $\mathrm{HC} 1$ of the rough lemon pathotype of A. alternata by PCR with a random primer set (RP-A30 primer, 5'-GACCTGCGATCT-3', and RP-A68 primer, 5'-GCGGAGGAACCA-3'). The 403-bp PCR product was subcloned into pT7Blue-2 (Novagen, Madison, WI). Digoxigenin (DIG)-labeling of DNA was performed with a DIG PCR-labeling kit (Roche, Mannheim, Germany) with the same primer sets, and hybridization and washing conditions for genomic Southern blotting were conducted under high stringency according to the manufacturer's instructions. Hybridization of the probes was visualized by antiDIG antibody-alkaline phosphatase and CSPD or SD-star (Roche) and by exposing the membranes to X-ray film (Fujifilm RX-U, Tokyo).

Preparation of protoplasts for pulse field gel electrophoresis. Fungal protoplasts were prepared by methods described previously (11) with modifications. Fungi grown on V8-juice agar plates were collected in $7 \mathrm{ml}$ of sterile distilled water, and all mycelia and spores collected were added to $50 \mathrm{ml}$ of PDB in 200-ml flasks. Mycelia were incubated at $28^{\circ} \mathrm{C}$ for $24 \mathrm{~h}$ with reciprocating shaking (125 rpm). Mycelia were harvested by centrifugation at 3,000 rpm for $5 \mathrm{~min}$. Pelleted mycelia were washed twice with $30 \mathrm{ml}$ of sterile distilled water and once with $30 \mathrm{ml}$ of osmotic (OM) buffer (1.2 $\mathrm{M} \mathrm{MgSO}_{4}$ and $\left.10 \mathrm{mM} \mathrm{Na}_{2} \mathrm{HPO}_{4}, \mathrm{pH} 5.8\right)$ by centrifugation at 4,000 rpm for $5 \mathrm{~min}$. Then mycelia were incubated in $5 \mathrm{ml}$ of sterile enzyme solution $(20 \mathrm{mg}$ of Lysing enzymes per $\mathrm{ml}$ [Sigma, St. Louis] and $3 \mathrm{mg}$ of kitalase per $\mathrm{ml}$ [Wako, Tokyo] in OM buffer) at $28^{\circ} \mathrm{C}$ for $6 \mathrm{~h}$ with shaking at $200 \mathrm{rpm}$. After incubation, the digested culture was transferred into 15-ml centrifuge tubes (Corning, Acton, MA) and overlain with $2 \mathrm{ml}$ of ST buffer $(0.6 \mathrm{M}$ sorbitol and $100 \mathrm{mM}$ Tris- $\mathrm{HCl}, \mathrm{pH}$ 8.0) and then centrifuged at $3,000 \mathrm{rpm}$ for $5 \mathrm{~min}$. Protoplasts banded at the interface of OM buffer and ST buffer were transferred to a new centrifuge tube (Corning). The protoplast suspension was mixed with $5 \mathrm{ml}$ of STC buffer (1 M sorbitol, $50 \mathrm{mM}$ $\mathrm{CaCl}_{2}$, and $50 \mathrm{mM}$ Tris- $\left.\mathrm{HCl}, \mathrm{pH} 8.0\right)$ and pelleted at 3,000 rpm for $5 \mathrm{~min}$. Protoplasts were washed twice with $5 \mathrm{ml}$ of SE buffer ( $1 \mathrm{M}$ sorbitol and $50 \mathrm{mM}$ EDTA) at 3,000 rpm for $5 \mathrm{~min}$. Protoplasts were resuspended in SE buffer and adjusted to a final concentration of $5.0 \times 10^{8}$ protoplasts per $\mathrm{ml}$. The protoplast solution was mixed with an equal volume of $1 \%$ low melting point agarose (Invitrogen, Carlsbad, CA) in SE buffer, and $100 \mu$ was pipetted into plug molds (Bio-Rad, Hercules, CA). Plugs were incubated in ET buffer (0.5 M EDTA and $10 \mathrm{mM}$ Tris- $\mathrm{HCl}, \mathrm{pH}$ $8.0)$ containing protease $\mathrm{K}(0.5 \mathrm{mg} / \mathrm{ml}$, Wako $)$ at $50^{\circ} \mathrm{C}$ for $48 \mathrm{~h}$. Plugs were washed three times for $1 \mathrm{~h}$ in $50 \mathrm{mM}$ EDTA and stored at $4^{\circ} \mathrm{C}$ until use.

Pulse field gel electrophoresis and Southern blot hybridization. Chromosomal DNA in the plugs was separated by pulse field gel electrophoresis (PFGE) using CHEF-DRII unit (BioRad). Agarose gels $(0.8 \%, 0.5 \times$ Tris-borate-EDTA [TBE]) were prepared with Seakem Gold agarose (BMA, Rockland, ME) and run in $0.5 \times \mathrm{TBE}$ buffer at $8^{\circ} \mathrm{C}$. Running conditions used to separate chromosomes of less than $6 \mathrm{Mb}$ were as follows: $1.5 \mathrm{~V} / \mathrm{cm}$ with pulse intervals of $3,600-1,800 \mathrm{~s}$ for $115 \mathrm{~h}, 1.5 \mathrm{~V} / \mathrm{cm}$ with pulse intervals of $1,800-1,300 \mathrm{~s}$ for $24 \mathrm{~h}, 1.8 \mathrm{~V} / \mathrm{cm}$ with pulse intervals of $1,300-800 \mathrm{~s}$ for $28 \mathrm{~h}$, and $2.4 \mathrm{~V} / \mathrm{cm}$ with pulse intervals of $800-600 \mathrm{~s}$ for $28 \mathrm{~h}$. Chromosomal size standards of Saccharomyces cerevisiae, Schizosaccharomyces pombe, and Hansenula wingei were obtained from Bio-Rad.

PFGE was used to isolate the $1.5 \mathrm{Mb}$ chromosome from isolate $\mathrm{HC} 1$ of the rough lemon pathotype. Running conditions used to separate chromosomes of less than $2 \mathrm{Mb}$ were as follows: $5.4 \mathrm{~V} / \mathrm{cm}$ with pulse intervals of $120 \mathrm{~s}$ for $13 \mathrm{~h}$ and $5.4 \mathrm{~V} / \mathrm{cm}$ with pulse intervals of $180 \mathrm{~s}$ for $13 \mathrm{~h}$. Saccharomyces cerevisiae and Schizosaccharomyces pombe chromosomes were used as size standards. DNA bands were visualized by ethidium bromide staining, and the $1.5 \mathrm{Mb}$ chromosome was excised from the gel and purified using NucleoTrap spin columns (Macherey-Nagel, Easton, PA) according to the manufacturer's instructions. The purified $1.5 \mathrm{Mb}$ chromosome from the rough lemon pathotype $\mathrm{HC} 1$ was used as the template for PCR with random primers.

For transfer of PFGE-separated chromosomes to nylon membranes for Southern hybridization, chromosomal DNA in PFGE gels was nicked with $0.2 \mathrm{~N} \mathrm{HCl}$ for 20 min and then soaked in $0.4 \mathrm{~N} \mathrm{NaOH}$ plus $1.5 \mathrm{M} \mathrm{NaCl}$ for 30 min with shaking at $50 \mathrm{rpm}$. DNA was transferred to Hybond $\mathrm{N}^{+}$membranes (Amersham Biosciences) for $48 \mathrm{~h}$ by alkaline capillary transfer (30) with $0.4 \mathrm{~N}$ $\mathrm{NaOH}$ plus $1.5 \mathrm{M} \mathrm{NaCl}$. Membranes were baked at $120^{\circ} \mathrm{C}$ for 30 min to fix the DNA. Membranes were washed once with sterile water at room temperature for $5 \mathrm{~min}$ and then twice with $0.2 \mathrm{~N} \mathrm{NaOH}$ plus $1 \%$ (vol/vol) sodium dodecyl sulfate at $40^{\circ} \mathrm{C}$ for $20 \mathrm{~min}$. Prehybridization was performed at $68^{\circ} \mathrm{C}$ for $30 \mathrm{~min}$. Probe labeling with the DIG PCR-labeling kit (Roche), hybridization, and washing conditions were conducted under high stringency according to the manufacturer's instructions. Hybridization of the probes was visualized as described previously.

\section{RESULTS}

Pathogenicity of isolate BC3-5-1-OS2A. The standard tangerine pathotype isolate $\mathrm{SH} 20$ induced necrotic symptoms only on the ACT-toxin-sensitive cv. Iyokan and produced no symptoms on leaves of rough lemon (Fig. 2A), whereas rough lemon pathotype isolate $\mathrm{HCl}$ was pathogenic only on rough lemon and not on Iyokan (Fig. 2A). BC3-5-1-OS2A was isolated from a leaf spot lesion on rough lemon, which is sensitive to ACR-toxin and susceptible to rough lemon pathotype isolate $\mathrm{HC} 1$. Isolate $\mathrm{BC} 3-5-$ 1-OS2A was pathogenic on both Iyokan tangor and rough lemon (Fig. 2A). BC3-5-1-OS2A was also pathogenic to Minneola and Seminole tangelos, which are sensitive to ACT-toxin and susceptible to the tangerine pathotype $(14,24)$.

Production of two HSTs by BC3-5-1-OS2A. The pathogenicity phenotype of isolate BC3-5-1-OS2A on both Iyokan tangor and rough lemon indicated the possibility that two distinct HSTs, ACT-toxin and ACR-toxin, are produced by this strain (Fig. 1). Since the culture filtrate of BC3-5-1-OS2A showed toxicity to both Iyokan tangor and rough lemon leaves by the leaf necrosis assay (Fig. 2B), the production of both ACT- and ACR-toxins was examined in further detail from ethyl acetate extracts of the culture filtrate by HPLC analysis for ACT-toxin and TLC analysis 
for ACR-toxin (Fig. 3). HPLC analysis detected a peak from the extract of BC3-5-1-OS2A that was equivalent to authentic ACTtoxin from the tangerine pathotype $\mathrm{SH} 20$ with a retention time of $19.5 \mathrm{~min}$ (Fig. 3A). TLC analysis also detected an equivalent spot for ACR-toxin from the extract of BC3-5-1-OS2A which was the same as authentic ACR-toxin from the rough lemon pathotype HC1 with an $R_{f}$ value of 0.24 (Fig. 3B). The recovered HPLC peak and TLC spot also showed identical host-selective toxicities to that of the authentic ACT- and ACR-toxins.

Presence of ACT-toxin-specific genes (ACTTS) in BC3-5-1OS2A. Southern hybridization with probes made from portions of the specific genes ACTT1 and ACTT2, present only in ACT-toxinproducing isolates (18), to genomic DNA of isolate BC3-5-1OS2A demonstrated that the ACTT probes hybridized to genomic DNA of both SH20 and BC3-5-1-OS2A, but not to genomic DNA of rough lemon isolate $\mathrm{HC} 1$ (Fig. 4). Hybridization patterns of the $A C T T$ probes to $\mathrm{SH} 20$ and $\mathrm{BC} 3-5-1-\mathrm{OS} 2 \mathrm{~A}$ were different. The $A C T T 1$ probe hybridized to two restriction fragments of 4.0 and $4.5 \mathrm{~kb}$ in $\mathrm{SH} 20$, but only to a single band of $4.3 \mathrm{~kb}$ in BC3-5-1OS2A. The ACTT2 probe hybridized to $1.5-, 2.0-, 3.5-$, and $6.0-\mathrm{kb}$
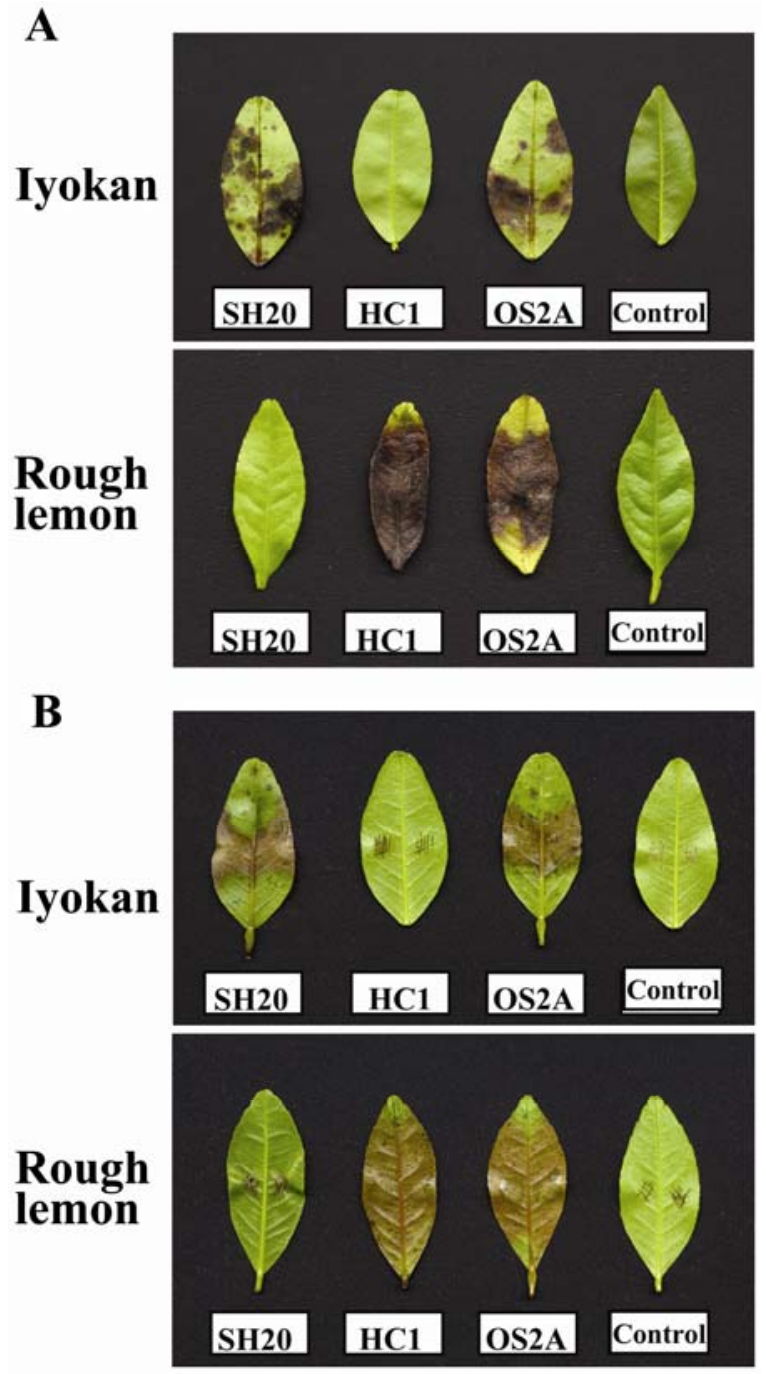

Fig. 2. Spray inoculation of isolate BC3-5-1-OS2A on leaves of Iyokan tangor and rough lemon. Leaves of rough lemon are sensitive to ACR-toxin and susceptible to the rough lemon pathotype of Alternaria alternata, while leaves of Iyokan tangor are sensitive to ACT-toxin and susceptible to the tangerine pathotype. A, Spray inoculation with conidia of the tangerine pathotype (isolate $\mathrm{SH} 20$ ), the rough lemon pathotype ( $\mathrm{HC} 1)$, or isolate $\mathrm{BC} 3-5-1-\mathrm{OS} 2 \mathrm{~A}$ (OS2A), or B, application of culture filtrates of each isolate to leaves. Water was used as a control and the leaves were incubated under the same conditions as respective treatments. bands in SH20 and to 1.5-, 2.0-, and 3.5-kb bands in BC3-5-1OS2A (Fig. 4).

To determine the chromosomal location of the ACT-toxin-specific genes, Southern hybridizations of transferred PFGE gels were performed (Fig. 5). The tangerine pathotype isolate SH20 had nine chromosomes ranging from 1.9 to $5.7 \mathrm{Mb}$ and gave an estimated total genome size of approximately $30 \mathrm{Mb}$ (Fig. 5). Isolate $\mathrm{BC} 3-5-1-\mathrm{OS} 2 \mathrm{~A}$ had 12 chromosomes ranging from 0.6 to $5.7 \mathrm{Mb}$ with a similar total genome size of about $30 \mathrm{Mb}$, but the
A

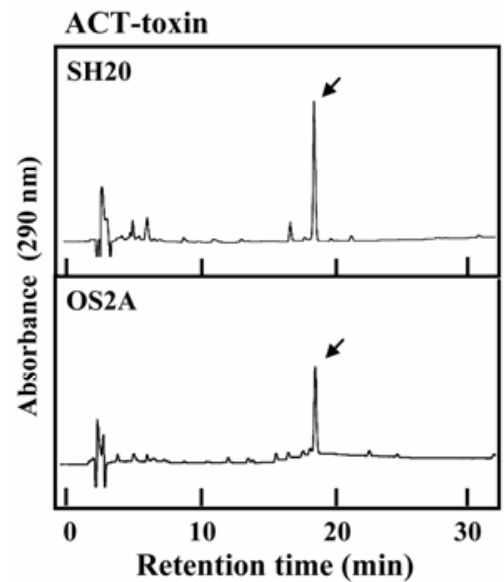

B

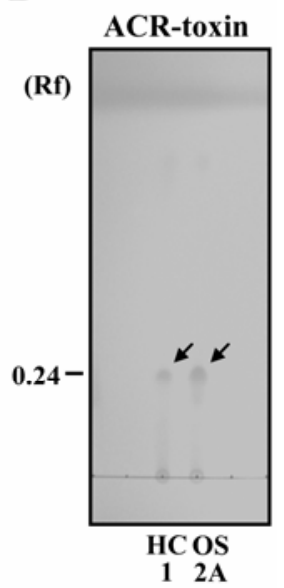

Fig. 3. High-performance liquid chromatography (HPLC) and thin-layer chromatography (TLC) determination of host-selective toxin (HST) production by Alternaria alternata isolate BC3-5-3-OS2A. HSTs produced by isolate BC3-5-3-OS2A (OS2A) were analyzed by A, HPLC for ACT-toxin and $\mathbf{B}$, TLC for ACR-toxin. Ethyl acetate extracts of culture filtrates from isolates of BC3-5-3-OS2A in modified Richards' medium $(15,16,18)$ were further analyzed by A, HPLC to detect ACT-toxin with a Develosil ODS-5 column (15). An authentic preparation of ACT-toxin (Fig. 1) was purified from culture filtrates of isolate $\mathrm{SH} 20$ (tangerine pathotype) by the method of Kohmoto et al. (15). The presence of ACR-toxin in the extracts was determined by TLC, and ACR-toxin was detected as a purple spot under $254 \mathrm{~nm}$ UV. The authentic preparation of ACR-toxin (Fig. 1) was purified from culture filtrates of isolate HC1 (rough lemon pathotype) by the method described previously $(2,4,19)$. Arrows indicate the corresponding peak for ACT-toxin in the HPLC chart in A and the corresponding spot of ACR-toxin on the TLC plate in $\mathbf{B}$.

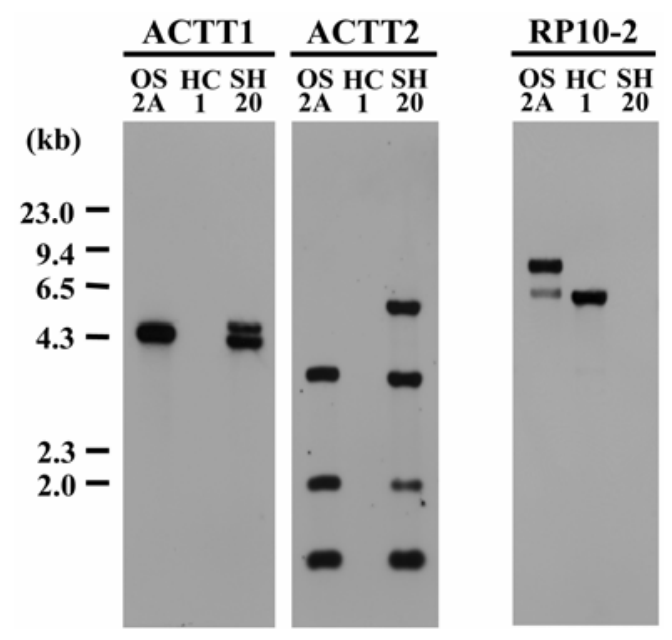

Fig. 4. Genomic Southern analysis of isolate BC3-5-3-OS2A. Total genomic DNA of Alternaria alternata isolate BC3-5-1-OS2A (OS2A), standard rough lemon pathotype isolate $\mathrm{HC} 1(\mathrm{HC} 1)$, and standard tangerine pathotype strain SH20 (SH20) digested with EcoRV were fractionated in $0.8 \%$ agarose gels and transferred to nylon membranes. Blots were hybridized with probes made from portions of the ACT-toxin producer-specific genes ACTT1 and ACTT2 or the RP10-2 region specific to ACR-toxin producers. Sizes of marker DNA fragments (HindIII-digested $\lambda$ DNA) are indicated at left. 
electrophoretic karyotype was different from that of SH20 (Fig. 5). The $0.6,1.05$, and $2.0 \mathrm{Mb}$ chromosomes in BC3-5-1-OS2A were completely missing from SH20 (Fig. 5). Both ACTT probes hybridized to the $1.05 \mathrm{Mb}$ chromosome in BC3-5-1-OS2A and to the $1.9 \mathrm{Mb}$ chromosome in SH20 (Fig. 5).

ACR-toxin-specific genomic region in BC3-5-1-OS2A. PFGE analysis of seven rough lemon pathotype isolates and several nonpathogenic A. alternata isolates revealed that all rough lemon pathotype isolates have unique chromosomes of 1.2 to $1.5 \mathrm{Mb}$ which are missing from all nonpathogenic A. alternata isolates (Fig. 6). The presence of this small chromosome was correlated with production of ACR-toxin and pathogenicity to rough lemon. A probe was made from a 408-bp PCR product following random priming of the isolated and purified 1.5 $\mathrm{Mb}$ chromosome from rough lemon pathotype isolate $\mathrm{HC}$. This probe, designated RP10-2, hybridized to genomic DNA and small chromosomes of the expected sizes from all rough lemon pathotype isolates and to BC3-5-1-OS2A but not to any tangerine pathotype isolates or nonpathogenic isolates (Figs. 4 to 6). RP10-2 was also used to probe genomic Southern blots containing genomic DNA of all known HST-producing Alternaria pathogens including the rough lemon, tangerine, Japanese pear, strawberry, tomato, apple, and tobacco pathotypes. RP10-2 hybridized to a 9.4-kb band with rough lemon pathotype isolates and not to any other pathotypes (Fig. 7). RP10-2 consists of a 403-bp genomic region (GenBank accession no. AB179713) that is located in the unique chromosome for the rough lemon pathotype. In BLAST searches, this sequence was $68 \%$ identical to a glucosyl transferase gene (GenBank accession no. E05633) from Aspergillus niger. Genes encoding glucosyl transferases are frequently closely linked to polyketide synthase gene clusters in fungi $(27,28,36)$.

This RP10-2 probe specific for the rough lemon pathotype was used to probe genomic Southern blots of isolate BC3-5-1-OS2A (Fig. 4). RP10-2 hybridized to genomic DNA of both $\mathrm{HC} 1$ and BC3-5-1-OS2A but not to genomic DNA from tangerine pathotype isolate $\mathrm{SH} 20$ (Fig. 4). The probe detected signals at 6.5 and $8.0 \mathrm{~kb}$ in BC3-5-1-OS2A but only a single $6.5-\mathrm{kb}$ band in $\mathrm{HC} 1$ (Fig. 4).

To determine which chromosome carried the ACR-toxin producer-specific gene in the rough lemon pathotype, PFGE and Southern blot hybridizations were carried out (Fig. 5). The RP102 probe specific to the $1.5 \mathrm{Mb}$ chromosome of the rough lemon pathotype $\mathrm{HC} 1$ hybridized to two chromosomes of 1.05 and 2.0 Mb in BC3-5-1-OS2A (Fig. 5).

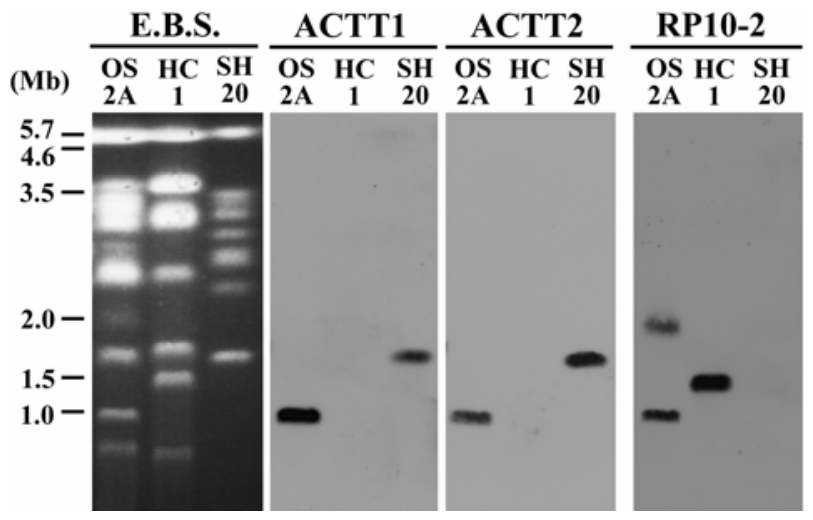

Fig. 5. Chromosomal location of ACTT genes and the RP10-2 region in isolate BC3-5-1-OS2A. Isolate BC3-5-1-OS2A (OS2A), standard rough lemon pathotype isolate $\mathrm{HC} 1$ (HC1), and standard tangerine pathotype strain $\mathrm{SH} 20$ (SH20) were determined by Southern blots of pulse field gel electrophoresis (PFGE). Sizes of Saccharomyces cerevisiae, Schizosaccharomyces pombe, and Hansenula wingei marker chromosomes are indicated at left. E.B.S. indicates the ethidium bromide-stained PFGE gel, and each panel shows hybridization with each probe.

\section{DISCUSSION}

Alternaria species are ubiquitous and cosmopolitan saprophytic and pathogenic fungi (29). Seven distinct pathotypes (pathogenic variants) of A. alternata are known that produce HSTs $(21,31$, 34,37). Despite the morphological similarity of these pathotypes, it is possible to distinguish them based on host range and this host specificity is due to the production of a particular HST (21). To our knowledge, this is the first report of a strain of A. alternata that is pathogenic to two different hosts and that produces two distinct HSTs, ACT-toxin and ACR-toxin. The quantity of each HST produced by $\mathrm{BC} 3-5-1-\mathrm{OS} 2 \mathrm{~A}$ in culture filtrates appears similar to that produced by each pathotype independently. The host ranges of A. alternata pathotypes are identical to the specificities of the purified HSTs $(21,31,34,37)$, and spray inoculation of BC3-5-1-OS2A on leaves of both ACT-toxin-sensitive and ACR-toxin-sensitive citrus cultivars resulted in necrosis on both cultivars. The dual host specificity and toxin production by BC3$5-1-O S 2 A$ is not common in populations of $A$. alternata on citrus. $\mathrm{BC} 3-5-1-\mathrm{OS} 2 \mathrm{~A}$ is the only isolate with pathogenicity to two different citrus hosts that has been found among hundreds of isolates examined to date $(18,24-26)$.

The expansion of host range may increase the fitness of pathogens because it increases their capacity for infection of and reproduction on a larger number of plant species. However, there may be a fitness cost to this expanded host range that limits the frequency of broad host range isolates like BC3-5-1-OS2A. One hypothesis is that one of the HSTs produced by BC3-5-1-OS2A could act as an elicitor of plant defense responses in toxininsensitive plants. For example, when BC3-5-1-OS2A infects rough lemon leaves, ACR-toxin functions as a pathogenicity factor while at the same time, ACT-toxin might act as an elicitor of defense responses in rough lemon. We have recently identified a possible role of ACT-toxin as an elicitor in the toxin-insensitive
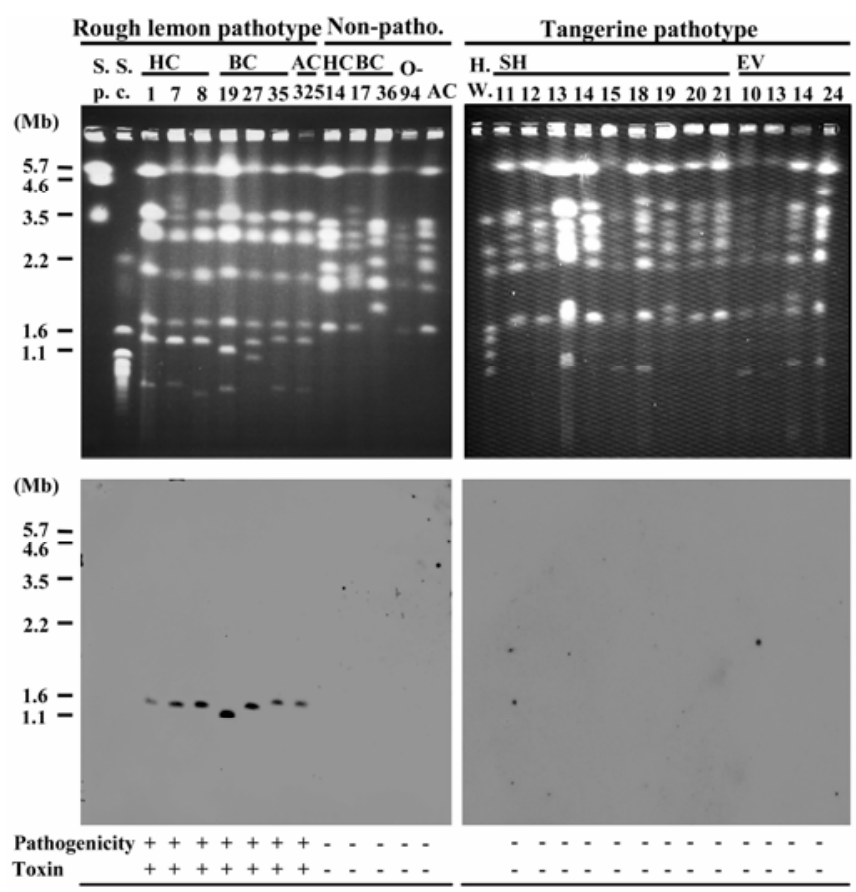

Fig. 6. Distribution of the RP10-2 region among field-collected pathogenic and nonpathogenic isolates of the rough lemon and tangerine pathotypes of Alternaria alternata as determined by pulse field gel electrophoresis and Southern blot. Rough lemon pathotypes are coded with $\mathrm{HC}, \mathrm{BC}$, and AC, and tangerine pathotypes are coded with $\mathrm{SH}$ and EV. Sizes of Saccharomyces cerevisiae, Schizosaccharomyces pombe, and Hansenula wingei marker chromosomes are indicated at left. Isolates producing ACR-toxin are indicated with a "+" and isolates pathogenic on rough lemon are also indicated with a "+" for pathogenicity at the bottom of the figures. 
cultivar of rough lemon $(5-9,20)$. Transcriptional analysis of several defense-related genes in rough lemon including lipoxygenase (6), hydroperoxide lyase (8), allene oxide synthase (8), epoxide hydrolase (7), polygalacturonase-inhibiting protein $(9,20)$, chalcone synthase (9), and chitinases (5) following inoculation with isolate $\mathrm{SH} 20$ induced higher transcript accumulation than nonpathogenic isolate O-94. Because there appear to be no major genetic differences, either morphologically or biochemically, between SH20 and O-94, except that SH20 produces ACT-toxin (15) that is toxic to tangerines but not to rough lemon $(2,3,14,15,18)$, ACT-toxin could be functioning as an elicitor in toxin-insensitive rough lemon. Although there is no significant difference found in necrosis caused by spray inoculation of BC3-5-1-OS2A and $\mathrm{HC} 1$ in the experiment described in this paper, a large number of conidia $\left(1 \times 10^{5}\right.$ conidia per $\left.\mathrm{ml}\right)$ were inoculated in this assay, and BC3-5-1-OS2A might have reduced fitness compared with that of the pathotype producing a single HST under natural conditions where infection by pathogen is likely initiated by infection of a single conidium.

We have demonstrated that a single isolate of A. alternata on citrus is able to cause disease on two distinct hosts and produce two distinct HSTs. These abilities appear to be conferred through the acquisition of two small chromosomes in the same nucleus. Phylogenetic analysis based on sequence data from three regions of the genome (26) has indicated that BC3-5-1-OS2A has a rough lemon pathotype genetic background, and there is no evidence that this isolate represents an ancestral form from which the rough lemon and tangerine pathotypes have evolved (T. L. Peever, unpublished data). BC3-5-1-OS2A is found in clade 3 of the combined phylogeny (26) containing several reference isolates of the rough lemon pathotype (T. L. Peever, unpublished data). However, BC3-5-1-OS2A has specific genes ACTT1 and ACTT2, present only in the tangerine pathotype producing ACT-toxin, as well as the genomic region, which is correlated with ACR-toxin producers of the rough lemon pathotype, on two small chromosomes of 1.05 and $2.0 \mathrm{Mb}$. The sizes of these small chromosomes appear similar to other small, conditionally dispensable chromo-

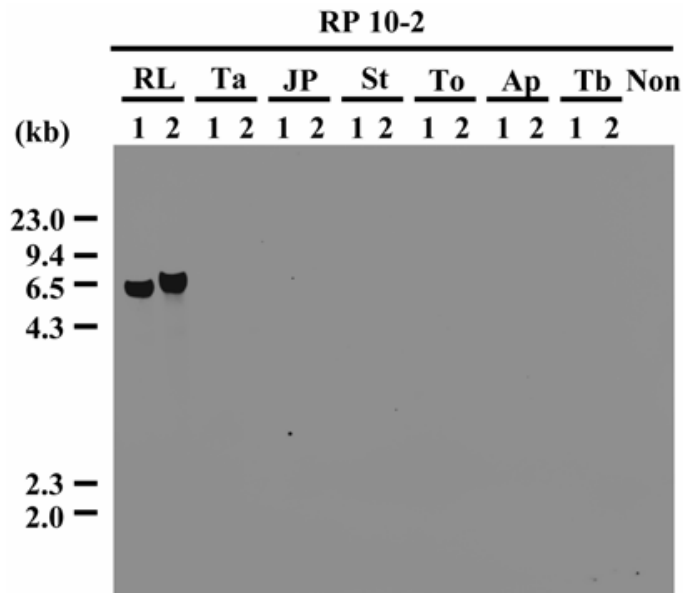

Fig. 7. Distribution of RP10-2 region among various host-selective toxin (HST)-producing isolates of Alternaria alternata. Total genomic DNA from HST-producing A. alternata pathotypes were digested with EcoRV and fractionated in $0.8 \%$ agarose gels. Blots were hybridized with the RP10-2 probe from the $1.5 \mathrm{Mb}$ chromosome specific to ACR-toxin producers. Sizes of marker DNA fragments (HindIII-digested $\lambda$ DNA) in kilobases are indicated at left. Abbreviations used in this figure are as follows: RL (rough lemon pathotype, isolates $\mathrm{HC} 1$ [lane 1] and AC325 [lane 2]), Ta (tangerine pathotype isolates SH14 [lane 1] and SH20 [lane 2]), JP (Japanese pear pathotype isolates 15A [lane 1] and Nu88-22 [lane 2]), St (strawberry pathotype isolates NAF-3 [lane 1] and NAF-8 [lane 2]), To (tomato pathotype isolates 91080804 [lane 1] and AL-4 [lane 2]), Ap (apple pathotype isolates O-159 [lane 1] andAM-1 [lane 2]), Tb (tobacco pathotype isolates 122-2 [lane 1] and AT-204 [lane 2]), and Non (nonpathogenic isolate O-94). somes $(<2 \mathrm{Mb})$ in Alternaria isolates that are related to production of HSTs and pathogenicity $(1,10,12,13)$. It is not known if the small chromosomes studied here are conditionally dispensable chromosomes but the lack of these chromosomes in nonpathogenic A. alternata isolates suggests that they are. The minimum chromosome size that carries all ACTT genes required for ACTtoxin biosynthesis is $1.1 \mathrm{Mb}$ for isolates from Turkey, South Africa, and Israel (A. Masunaka and K. Akimitsu, unpublished data), and the $1.05 \mathrm{Mb}$ of $\mathrm{BC} 3-5-1-\mathrm{OS} 2 \mathrm{~A}$ is similar to this size. The pathotype-specific HST genes studied here will be useful for population genetic studies of these fungi as well as for molecular evolution studies of toxin genes.

All tested isolates causing leaf spot of rough lemon that produce ACR-toxin carry the RP10-2 genomic region. This region occurs on the $1.5 \mathrm{Mb}$ chromosome of isolate $\mathrm{HC} 1$, whereas all non-ACR-toxin-producing strain including all other HST-producing Alternaria pathotypes (rough lemon, tangerine, Japanese pear, strawberry, tomato, apple, and tobacco pathotypes) and nonpathogenic A. alternata do not have this sequence in their genomes. ACR-toxin is a polyketide and we hypothesize that the production of this toxin is under the control of a polyketide synthase that may be part of the toxin biosynthesis cluster controlling ACR-toxin biosynthesis. A BLAST search revealed that RP10-2 likely encodes a glycosyl transferase, a gene that is often tightly linked to the polyketide synthase gene in the genomes of filamentous fungi $(27,28,36)$. It may be possible to exploit this linkage to clone and characterize the genes responsible for ACR-toxin biosynthesis. We have isolated several bacterial artificial chromosome clones from a genomic library of isolate $\mathrm{HC} 1$ using RP10-2 as a probe and are currently sequencing and performing functional analysis of the region surrounding RP10-2 on the $1.5 \mathrm{Mb}$ chromosome (A. Masunaka and K. Akimitsu, unpublished data).

The $1.05 \mathrm{Mb}$ chromosome of BC3-5-1-OS2A carries portions of at least two distinct gene clusters responsible for the production of both ACR- and ACT-toxins because ACTT probes as well as the RP10-2 probe hybridized to this same chromosome. The acquisition of both toxin gene clusters by isolate BC3-5-1-OS2A may have resulted in rearrangement of the genes in the clusters such as duplication or dispersal through unequal crossing over or translocation. Comparisons of chromosomal organization and toxin sequences between the $1.9 \mathrm{Mb}$ chromosome of isolate $\mathrm{SH} 20,1.5 \mathrm{Mb}$ chromosome of isolate $\mathrm{HC} 1$, and $1.05 \mathrm{Mb}$ chromosome of isolate BC3-5-1-OS2A may give some insight into the evolution of toxin production and pathogenicity as well as the evolution of eukaryotic genomes.

\section{ACKNOWLEDGMENTS}

This study was supported in part by grants from the Ministry of Education, Culture, Sports, Science and Technology of Japan, the Japanese Society for the Promotion of Science, and PRESTO, Japan Science and Technology Agency. Nucleotide sequence of the 403-bp region specific for the rough lemon pathotype can be found in the DDBJ, EMBL, and GenBank databases under accession number AB179713.

\section{LITERATURE CITED}

1. Akamatsu, H., Taga, M., Kodama, M., Johnson, R. D., Otani, H., and Kohmoto, K. 1999. Molecular karyotypes for Alternaria plant pathogens known to produce host-specific toxins. Curr. Genet. 35:647-656.

2. Akimitsu, K., Kohmoto, K., Otani, H., and Nishimura, S. 1989. Hostspecific effect of toxin from the rough lemon pathotype of Alternaria alternata on mitochondria. Plant Physiol. 89:925-931.

3. Akimitsu, K., Peever, T. L., and Timmer, L. W. 2003. Molecular, ecological and evolutionary approaches to understanding Alternaria diseases of citrus. Mol. Plant Pathol. 4:435-446.

4. Gardner, J. M., Kono, Y., Tatum, J. H., Suzuki, Y., and Takeuchi, S. 1985. Structure of major component of ACRL toxins, host-specific phytotoxic compound produced by Alternaria citri. Agric. Biol. Chem. 49:12351238 . 
5. Gomi, K., Itoh, N., Yamamoto, H., and Akimitsu, K. 2002. Characterization and functional analysis of class I and II acidic chitinase cDNA from rough lemon. J. Gen. Plant Pathol. 68:191-199.

6. Gomi, K., Yamamoto, H., and Akimitsu, K. 2002. Characterization of lipoxygenase gene in rough lemon induced by Alternaria alternata. J. Gen. Plant Pathol. 68:21-30.

7. Gomi, K., Yamamoto, H., and Akimitsu, K. 2003. Epoxide hydrolase: A mRNA induced by a fungal pathogen Alternaria alternata on rough lemon (Citrus jambhiri Lush). Plant Mol. Biol. 53:189-199.

8. Gomi, K., Yamasaki, Y., Yamamoto, H., and Akimitsu, K. 2003. Characterization of citrus hydroperoxide lyase gene and effect of $\mathrm{C}_{6}$-volatiles on expression of oxylipin-metabolizing enzyme genes. J. Plant Physiol. 160:1219-1231.

9. Gotoh, Y., Nalumpang, S., Isshiki, A., Utsumi, T., Gomi, K., Yamamoto, H., and Akimitsu, K. 2002. A cDNA encoding polygalacturonase-inhibiting protein induced in citrus leaves by polygalacturonase of Alternaria citri. J. Gen. Plant Pathol. 68:57-61.

10. Hatta, R., Ito, K., Hosaki, Y., Tanaka, T., Tanaka, A., Yamamoto, M., Akimitsu, K., and Tsuge, T. 2002. A conditionally dispensable chromosome controls host-specific pathogenicity in the plant pathogenic fungus Alternaria alternata. Genetics 161:59-70.

11. Isshiki, A., Akimitsu, K., Yamamoto, M., and Yamamoto, H. 2001. Endopolygalacturonase is essential for citrus black rot caused by Alternaria citri but not brown spot caused by Alternaria alternata. Mol. PlantMicrobe Interact. 14:749-757.

12. Ito, K., Tanaka, T., Hatta, R., Yamamoto, M., Akimitsu, K., and Tsuge, T. 2004. Dissection of the host range of the fungal plant pathogen Alternaria alternata by modification of the secondary metabolism. Mol. Microbiol. 52:399-411.

13. Johnson, L., Johnson, R. D., Akamatsu, H., Salamiah, A., Otani, H., Kohmoto, K., and Kodama, M. 2001. Spontaneous loss of a conditionally dispensable chromosome from Alternaria alternata apple pathotype leads to loss of toxin production and pathogenicity. Curr. Genet. 40:65-72.

14. Kohmoto, K., Akimitsu, K., and Otani, H. 1991. Correlation of resistance and susceptibility of citrus to Alternaria alternata with sensitivity to hostspecific toxins. Phytopathology 81:719-722.

15. Kohmoto, K., Itoh, Y., Shimomura, N., Kondoh, Y., Otani, H., Kodama, M., Nishimura, S., and Nakatsuka, S. 1993. Isolation and biological activities of two host-specific toxins from the tangerine pathotype of Alternaria alternata. Phytopathology 83:495-450.

16. Kohmoto, K., Scheffer, R. P., and Whiteside, J. O. 1979. Host-selective toxins from Alternaria citri. Phytopathology 69:667-671.

17. Lu, S., Lyngholm, L., Yang, G., Bronson, C., Yoder, O. C., and Turgeon, B. G. 1994. Tagged mutations at the Tox1 locus of Cochliobolus heterostrophus by restriction enzyme-mediated integration. Proc. Natl. Acad. Sci. USA 91:12649-12653.

18. Masunaka, A., Tanaka, A., Tsuge, T., Peever, T. L., Timmer, L. W., Yamamoto, M., Yamamoto, H., and Akimitsu, K. 2000. Distribution and characterization of AKT homologs in the tangerine pathotype of Alternaria alternata. Phytopathology 90:762-768.

19. Nakatsuka, S., Goto, T., Kohmoto, K., and Nishimura, S. 1986. Hostspecific phytotoxins. Pages 11-18 in: Natural Products and Biological Activities. H. Imura, T. Goto, T. Murachi, and T. Nakajima, eds. University of Tokyo Press, Tokyo.
20. Nalumpang, S., Gotoh, Y., Tsuboi, H., Gomi, K., Yamamoto, H., and Akimitsu, K. 2002. Functional characterization of citrus polygalacturonase-inhibiting protein. J. Gen. Plant Pathol. 68:118-127.

21. Nishimura, S., and Kohmoto, K. 1983. Host-specific toxins and chemical structures from Alternaria species. Annu. Rev. Phytopathol. 21:87-116.

22. Ohtani, K., Yamamoto, H., and Akimitsu, K. 2002. Sensitivity to Alternaria alternata toxin in citrus because of altered mitochondrial RNA processing. Proc. Natl. Acad. Sci. USA 99:2439-2444.

23. Palm, M. E., and Civerolo, E. L. 1994. Isolation, pathogenicity and partial host range of Alternaria limicola, causal agent of mancha foliar de los citricos in Mexico. Plant Dis. 78:879-883.

24. Peever, T. L., Canihos, Y., Olsen, L., Ibáñez, A., Liu, Y.-C., and Timmer, L. W. 1999. Population genetic structure and host specificity of Alternaria spp. causing brown spot of Minneola tangelo and rough lemon in Florida. Phytopathology 89:851-860.

25. Peever, T. L., Olsen, L., Ibáñez, A., and Timmer, L. W. 2000. Genetic differentiation and host specificity among populations of Alternaria spp. causing brown spot of grapefruit and tangerine $\times$ grapefruit hybrids in Florida. Phytopathology 90:407-414.

26. Peever, T. L., Su, G., Carpenter-Boggs, L., and Timmer, L. W. 2004 Molecular systematics of citrus-associated Alternaria species. Mycologia 96:119-134.

27. Raty, K., Kantola, J., Hautala, A., Hakala, J., Ylihonko, K., and Mantsala, P. 2002. Cloning and characterization of Streptomyces galilaeus aclacinomycins polyketide synthase (PKS) cluster. Gene 293:115-122.

28. Rix, U., Fischer, C., Remsing, L. L., and Rohr, J. 2002. Modification of post-PKS tailoring steps through combinatorial biosynthesis. Nat. Prod. Rep. 19:542-580.

29. Rotem, J. 1994. Biology, The Genus Alternaria. Pages 1-10 in: Epidemiology and Pathogenicity. The American Phytopathological Society, St. Paul, MN.

30. Sambrook, J., Fritsch, E. F., and Maniatis, T. 1989. Molecular Cloning: A Laboratory Manual. 2nd ed. Cold Spring Harbor Laboratory, Cold Spring Harbor, NY.

31. Scheffer, R. P., and Livingston, R. S. 1984. Host-selective toxins and their role in plant diseases. Science 223:17-21.

32. Tanaka, A., Shiotani, H., Yamamoto, M., and Tsuge, T. 1999. Insertional mutagenesis and cloning of the genes required for biosynthesis of the host-specific AK-toxin in the pear pathotype of Alternaria alternata. Mol. Plant-Microbe Interact. 12:691-702

33. Timmer, L. W., Peever, T. L., Dolel, Z., and Akimitsu, K. 2003. Alternaria diseases of citrus-Novel pathosystems. Phytopathol. Mediterr. 42:99-112.

34. Walton, J. D. 1996. Host-selective toxins: Agents of compatibility. Plant Cell 8:1723-1733.

35. Wolpert, T. J., Dunkle, L. D., and Ciuffetti, L. M. 2003. Host-selective toxins and avirulence determinants: What's in a name? Annu. Rev. Phytopathol. 40:251-285.

36. Xue, Y., Zhao, L., Liu, H. W., and Sherman, D. H. 1998. A gene cluster for macrolide antibiotic biosynthesis in Streptomyces venezuelae: Architecture of metabolic diversity. Proc. Natl. Acad. Sci. USA 95:1211112116.

37. Yoder, O. C. 1980. Toxins in pathogenesis. Annu. Rev. Phytopathol. 18:103-129. 